\title{
Plasma Treatment of Agave Fiber Powder and Its Effect on the Mechanical and Thermal Properties of Composites Based on Polyethylene
}

\author{
Florentino Soriano Corral, ${ }^{1}$ Luis Antonio Calva Nava, ${ }^{1}$ \\ Ernesto Hernández Hernández, ${ }^{2}$ José Francisco Hernández Gámez, ${ }^{2}$ \\ María Guadalupe Neira Velázquez, ${ }^{1}$ María Isabel Montalvo Sierra, ${ }^{3}$ \\ Pablo González Morones, ${ }^{1}$ and Ramón Enrique Díaz De León Gómez ${ }^{1}$ \\ ${ }^{1}$ Centro de Investigación en Química Aplicada (CIQA), Blvd. Enrique Reyna H. 140, 25294 Saltillo, COAH, Mexico \\ ${ }^{2}$ CONACYT, Centro de Investigación en Química Aplicada, Blvd. Enrique Reyna H. 140, 25294 Saltillo, COAH, Mexico \\ ${ }^{3}$ Universidad Politécnica de Pachuca (UPP), Carretera Pachuca-Cd., Sahagún km. 20, Rancho Luna S/N, \\ 43830 Zempoala, HGO, Mexico
}

Correspondence should be addressed to Florentino Soriano Corral; florentino.soriano@ciqa.edu.mx

Received 6 September 2016; Revised 16 November 2016; Accepted 29 November 2016

Academic Editor: Nabil Ibrahim

Copyright (C) 2016 Florentino Soriano Corral et al. This is an open access article distributed under the Creative Commons Attribution License, which permits unrestricted use, distribution, and reproduction in any medium, provided the original work is properly cited.

Composites based on low-density polyethylene (LDPE) were prepared with Agave fiber powder (AFP) that was coated by plasma polymerization process using ethylene gas. Treated and pristine AFP were analyzed by infrared spectroscopy, scanning electron microscopy, and contact water angle for the assessment of surface properties. The polymer composites were prepared by melt mixing using $0,5,10$, and $20 \mathrm{wt} \%$ of AFP and their mechanical and thermal properties were measured. Dispersion evaluation in water confirmed that the AFP treated changed from hydrophilic to hydrophobic behavior and it was also corroborated with water contact angle tests. The addition of treated and untreated AFP (200 mesh) at $20 \mathrm{wt} \%$ promotes an increase of Young's modulus of the composites of up to $60 \%$ and $32 \%$, respectively, in relation to the neat matrix. Also, an increase of crystallinity of LDPE was observed by the addition of treated and untreated AFP; however no significant effect on the crystallization temperature was observed in LDPE containing AFP.

\section{Introduction}

Natural fibers are suitable materials to reinforce synthetic polymers, such as thermosets and thermoplastics, because they exhibit a relatively high strength, high stiffness, and low density [1]. These fibers are biodegradable and are available from a renewable source and have special advantages in comparison with other synthetic fibers. A large variety of natural fibers are available around the world, but they are not compatible with most polymers and as a consequence they require a chemical or physical treatment in order to promote interfacial interactions with the polymer matrices. Agave tequilana Weber azul is an economically important specie cultivated in Mexico and is the only one of the species of Agavaceae that is appropriate for the production of tequila. After the juice extraction process is carried out, fibers from Agave are disposed and they become a serious waste problem. From the total wet weight of the agave plant, 54\% represents the agave head, which is the raw material for tequila production; the rest of the wet plant $(46 \%)$ is not used and typically it is left in the fields and became a potential source of mosquito breeding [2]. In the year 2013 the production of Agave to extract tequila was 756,900 tons [3] and approximately $60 \%$ of this amount was discarded.

Several researchers have been studying the use of agave fibers $(\mathrm{AF})$ as reinforcement in some polymeric matrices. 
For example, Aranda and coworkers studied the behavior of composites based on thermoplastic starch with different contents of agave bagasse fibers (0-15 wt\%) and polylactic acid (PLA). The results showed that thermoplastic starch hygroscopicity decreased as PLA and fiber content increased. Storage, stress-strain, and flexural modulus increased with PLA and/or agave bagasse fibers content, while the impact resistance decreased [4]. In another study conducted by Singha and coworkers, they modified AF and mixed it with a polystyrene matrix. The effect of different fiber dimensions (particles, short and long fibers) on the mechanical properties of the composites was also investigated herein. Particles of fibers give better mechanical properties than short and long fibers [5]. In other work, AF were modified by maleic anhydride grafted polyethylene and mixed with LDPE. It was found that tensile and flexural modulus increased with treated AF concentration, while the impact strength of the composites decreased [6]. Guzmán and coworkers also prepared composites based on LDPE with AF at contents of 5, 10, and $20 \mathrm{wt} \%$ and processed the composites at several temperature profiles; their results showed that Young's modulus of the composites increased with fiber content but decreased linearly with the increment of processing temperatures due to the fiber degradation [7].

The application of natural fillers can be seen as an approach to adjust material performance of polymer composites assuming that filler/matrix interactions will be optimized and a hygroscopicity of natural fillers will be hindered. Plasma technology has demonstrated its potential to modify the surface properties of polymers, nanoparticles, and natural fibers among others [8-10]. Previously, different authors had reported the advantages of plasma treatment in natural fibers to improve their interfacial adhesion with different polymers [11]. For example, argon and air plasma treatment improve the compatibility between wood fibers $(20 \mathrm{wt} \%)$ and polypropylene increasing the tensile strength and Young's modulus in $13 \%$ and $150 \%$, respectively, due to oxygen groups deposited on the surface of wood fibers during plasma treatment [12]. Other authors used oxygen plasma treatment to modify the surface of jute fiber and they found a direct dependence of the plasma power conditions on the interfacial adhesion of the fiber with high density polyethylene (HDPE). For example, when the jute fabric was treated at a plasma power of $30 \mathrm{~W}$, the flexural strength increased up to a value of $39.7 \mathrm{MPa}$. Increasing the plasma power to $60 \mathrm{~W}$ resulted in greatest flexural strength $(45.6 \mathrm{MPa})$ value, in relation to the value of HDPE/untreated jute composites (31.4 MPa) [13]. When a monomer like styrene was used to plasma-treat the surface of cellulose fibers for 4 minutes, Young's modulus of the composites increased in about $44 \%$ and the treatment promoted the compatibility with polystyrene due to the plasma coating of styrene monomer deposited at the surface of cellulose fibers [14]. In the same way, in our previous work [15] we obtained an increase in Young's modulus up to $60 \%$ in composites based polyethylene as a result of the surface modification of agave fibers by ethylene plasma; a good dispersion and compatibility were observed in the composites. The treatment of natural fibers by plasma polymerization process also could reduce the humidity absorption of the fibers, and this is an important issue to use the natural fibers for different applications.

The aim of the present work is to study systematically the effect of treatment of AFP by ethylene plasma on the mechanical and thermal properties in polymer composites based on low-density polyethylene.

\section{Experimental}

2.1. Materials. LDPE (PX 20020 P) with a density of $0.92 \mathrm{~g} / \mathrm{cm}^{3}$ and a melt flow index of $0.2 \mathrm{~g} / 10 \mathrm{~min}$ was supplied by Petroleos Mexicanos (PEMEX). Agave fiber (AF) was provided by Solyagave S. A. de C. V, and to obtain Agave fiber powder (AFP), AF was grinded and separated in sieves of 200 and 325 mesh by Ro-tap test sieve shaker. The contents of Agave fiber powder used in the polymer composites were 5,10 , and $20 \mathrm{wt} \%$. The ethylene gas monomer used for the plasma polymerization process was kindly supplied by Infra (Mexico).

2.2. Plasma Treatment. The plasma treatment of the AFP was carried out in a round bottom flask $(500 \mathrm{~mL})$ with a copper wire coiled around the wall of the flask, acting as an inductive electrode. One of the ends of the copper wire was connected to a radio frequency generator (Advanced Energy RFX600). The plasma treatment of AFP was carried out as follows: $7 \mathrm{~g}$ of AFP and a magnetic stirrer were introduced into the round bottom flask, which was then connected to the vacuum system. The initial internal pressure in the flask was $28 \mathrm{~Pa}$. During the plasma treatment, the ethylene gas flow rate was fixed at $0.16 \mathrm{~cm}^{3} \mathrm{~min}^{-1}$ while the internal pressure was increased to $50 \mathrm{~Pa}$. The plasma process conditions were $40 \mathrm{~W}$ of input plasma power and 60 min of treatment time. More details of this plasma reactor can be found in [16].

2.3. Formulation of Polymer Blends. The composites were prepared in a Brabender plasticorder mixing chamber $\left(75 \mathrm{~cm}^{3}\right)$ with a CAM type rotor, and the blends were prepared at $60 \mathrm{rpm}$ and $160^{\circ} \mathrm{C}$ for $15 \mathrm{~min}$. First, LDPE was placed in the heated chamber; then the AFP were added and mixed for $15 \mathrm{~min}$.

2.4. Specimen Preparation. For the mechanical tests, samples with a thickness of $2 \mathrm{~mm}$ were prepared by compression molding in a PHI thermal hot platens model Q230H-X4A at $160^{\circ} \mathrm{C}$ and a load of 20 ton and were cooled under the same pressure conditions by circulating water through the platens.

The mechanical tests were carried out in accordance with ASTM D-638, in a SMF-120 tensile apparatus, using a strain rate of $50 \mathrm{~mm} / \mathrm{min}$ at $25^{\circ} \mathrm{C}$. Six specimens per experiment were previously conditioned at $23 \pm 2^{\circ} \mathrm{C}$ for $40 \mathrm{~h}$, at $50 \pm 5 \%$ of relative humidity.

The grinded AF with and without plasma treatment was analyzed by infrared spectroscopy using a PerkinElmer FTIR spectrometer, coupled to an attenuated total reflectance unit (ATR-IR). The infrared analyses were performed with a resolution of $4 \mathrm{~cm}^{-1}$ and 20 scans. 
Differential scanning calorimetry (DSC) analyses of composites were carried out in an equipment (Discovery Series) from TA instruments, at a heating rate of $10^{\circ} \mathrm{C} \mathrm{min}^{-1}$ in a temperature interval from 0 to $200^{\circ} \mathrm{C}$, in a nitrogen atmosphere with a flow rate of $50 \mathrm{~mL} / \mathrm{min}$. The degree of crystallinity (in percentage) of the LDPE was determined using

$$
X_{c}=\frac{\Delta H_{m}^{*}}{\Delta H_{m}(1-\emptyset)} \times 100,
$$

where $\Delta H_{m}{ }^{*}$ is the fusion enthalpy of the composite determined by DSC, $\Delta H_{m}$ is the enthalpy of the PE with a crystallinity of $100 \%$ that is reported as $293 \mathrm{~J} \mathrm{~g}^{-1}$ [17], and " $\varnothing$ " is the weight fraction of the dispersed phase in the composite.

The morphology of the composites was determined using a Topcon SM510 scanning electron microscope (SEM). The samples were cryogenically fractured, and previous to the analysis, samples were coated with $\mathrm{Au}$-Pd to reduce the charge effect.

\section{Results and Discussion}

3.1. Infrared Spectroscopy Analysis of AFP. Figure 1 shows the ATR-IR spectrum of the AFP unmodified (Figure 1(A)) as well as the ATR-IR spectrum of AFP modified by plasma (Figure 1(B)). The first broad band located at $3400 \mathrm{~cm}^{-1}$ is due to the stretching vibrations of hydroxyl groups from the cellulose present in the AFP; the band located at $2920 \mathrm{~cm}^{-1}$ is related to $\mathrm{C}-\mathrm{H}$ stretching of the aliphatic methylene groups [18]. The weak peak at $1730 \mathrm{~cm}^{-1}$ is attributed to hemicellulose, associated with the $\mathrm{C}=\mathrm{O}$ stretching in nonconjugated ketones, ester groups, and carbonyls [19]. The band located at $1640 \mathrm{~cm}^{-1}$ is attributed to the $\mathrm{C}=\mathrm{O}$ stretching vibration and the $\mathrm{C}=\mathrm{C}$ stretching vibration from alkenes groups and aromatic compounds [20]. Aromatic structure vibration from lignin and lignocellulose presents a band between 1510 and $1520 \mathrm{~cm}^{-1}$ [21]. Peaks at 1250 and $1000 \mathrm{~cm}^{-1}$ are related to $\mathrm{C}-\mathrm{O}-\mathrm{C}$ and $\mathrm{C}-\mathrm{O}$ stretching vibrations on the cellulose chain bone [22]. Finally, the band at $1080 \mathrm{~cm}^{-1}$ associated with the stretch vibration of $\mathrm{C}-\mathrm{O}$ is attributed to polysaccharides and hemicelluloses as reported previously by Grube and Bodirlau, respectively $[23,24]$.

In relation to the plasma treated AFP, the same infrared signals were observed in both fibers (pristine and coated). Typically, the amount of these plasma films on the surface of materials is lower than $5 \mathrm{wt} \%$ in relation to the substrate, and therefore it is difficult to observe infrared signals of the deposit, since it is beyond the limit of detection of FTIR. Another reason is that the films synthesized by plasma polymerization present a low relation H/C (aprox 1.49) against monomer (2) as has been shown previously by other authors [25], and this fact suggests that the polymeric nanofilm has a highly crosslinked structure and therefore a difference between two spectral signals cannot be seen.

In literature, it has been reported that the plasma treatment polymer or plasma coating suffers a partial oxidation due to a reaction with atmospheric oxygen or water vapor after removal of the treated substrate from the vacuum

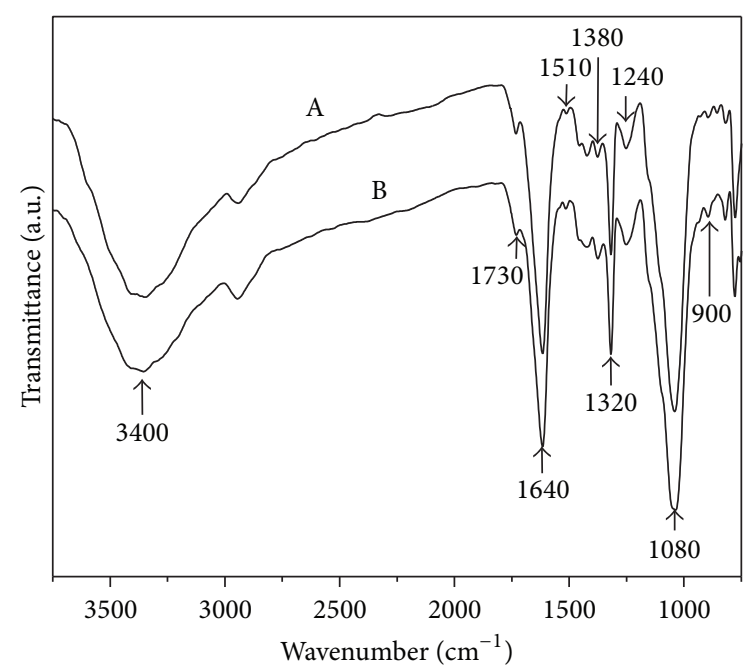

FIGURE 1: FTIR spectra of (A) pristine AFP and (B) AFP modified by plasma.

chamber or even with oxygen dissolved in the monomers [25, 26]. These signals associated with the oxidation of polymer films deposited on the surface of the fiber powder by plasma were not detected by infrared due to possible overlap with bands of the AFP.

The change on the surface characteristics of AFP after the plasma treatment was measured qualitatively through water dispersion tests in water. The untreated AFP are very well dispersed in water (see Figure 2, left) and this behavior is due to the polar groups present in cellulose, which promotes the hydrophilic character of AFP. Meanwhile, plasma treated AFP remains on the water surface up to 2 months indicating that the fibers have a hydrophobic behavior (Figure 2, right). The above can be explained by the presence of a plasma polyethylene thin film coating located at the AFP surface, which inhibits the interaction between the surface of treated AFP and water. This kind of polymeric layer had been reported by several researchers, who have demonstrated that the presence of the plasma polymer at the surface of a substrate reduces the moisture and oxygen permeability, both of which are related to the density and structure of the plasma polymer thin film coatings $[27,28]$. The cross-linked structure of polyethylene synthesized by plasma and its low concentration of oxygen in their structure could explain the long time stability of the hydrophobic behavior of treated AFP.

Another evidence that corroborated the hydrophobic character of the plasma treated AFP was the contact angle measurement and it was $75^{\circ}$ approximately. In case of the untreated AFP no contact angle was formed due to the fast absorption of water drop by the agave fibers indicating thus their hydrophilic behavior. It is well known that plasma treatments can change the polarity of several types of fibers and improve their compatibility towards different polymer matrix [29]; this indicates that plasma treatment with ethylene reduces the surface energy, and thus the treated fibers present lower wettability than pristine fibers; also the film coating deposited on the fibers presents low polarity. 


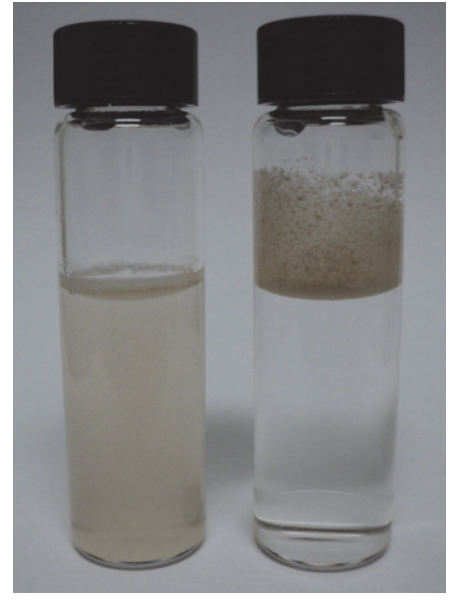

FIGURE 2: Dispersion test of AFP in water. Left: untreated AFP; right: plasma treated AFP (hydrophobic behavior of the plasma treated samples remains upon two months).

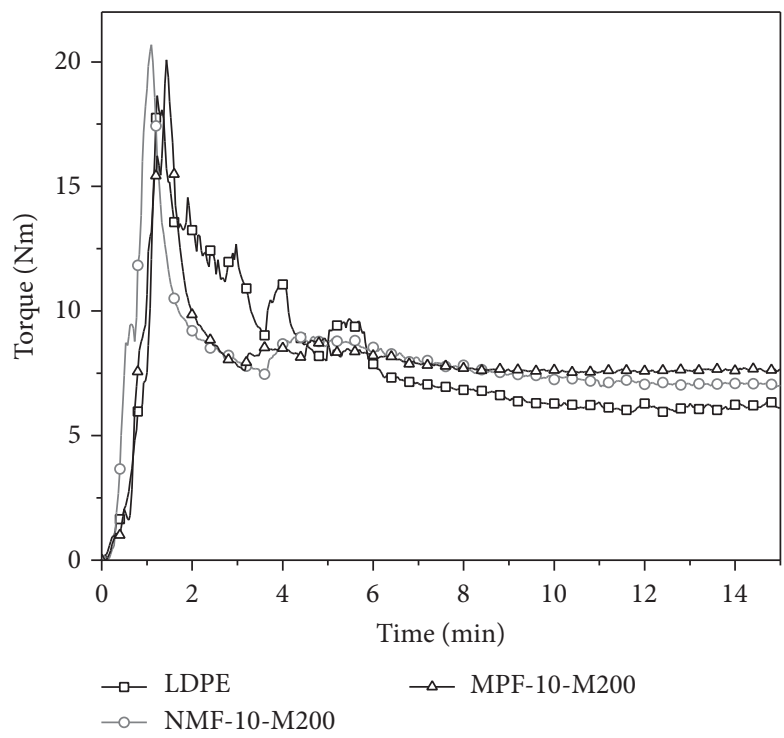

FIgURE 3: Torque-time curves of the blends containing $10 \mathrm{wt} \%$ of unmodified and plasma treated AFP.

3.2. Mixing Torque. The torque-time curves during the preparation of the composites in melt state are presented in Figure 3; at LDPE feeding, an increase in the torque value of up to $20 \mathrm{Nm}$ can be identified; then it diminished to $10 \mathrm{Nm}$ at $2 \mathrm{~min}$, and it lastly is associated with the melting of LDPE pellets. In the interval from 4 to $6 \mathrm{~min}$ there was some increase of the values of torque associated with the addition of the AFP. This means that the presence of AFP increases the melt viscosity of the mixture. After $6 \mathrm{~min}$, the intermolecular forces and physical entanglement between the adjacent molecules decrease, and an equilibrium value (obtained at $12 \mathrm{~min}$ ) for a torque of $6.09 \pm 0.09 \mathrm{Nm}$ was achieved for LDPE; meanwhile the torque values for the blends with $10 \mathrm{wt} \%$ of AFP $(200$ mesh) modified (MPF-10-M200) and unmodified (NMF-10M200) were $7.59 \pm 0.02$ and $7.08 \pm 0.02 \mathrm{Nm}$, respectively. The

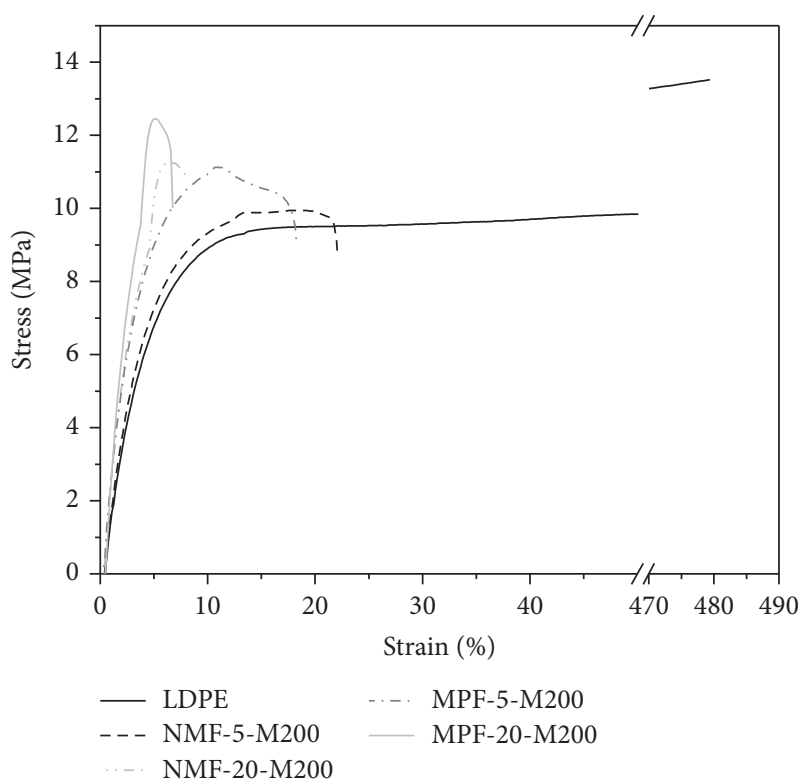

FIGURE 4: Tensile stress-strain curves of the blends containing 5 and $20 \mathrm{wt} \%$ of AFP unmodified and modified by plasma.

slightly higher value of torque in MPF-10-M200 in relation to NMF-10-M200 is attributed to the higher interactions between melt molecules of LDPE and plasma treated AFP. The same behavior is presented at higher contents of AFP; higher values of torque were observed for the blends containing $20 \mathrm{wt} \%$ of AFP ( $200 \mathrm{mesh}$ ) in relation to those contained $10 \mathrm{wt} \%$ and the values were $8.36 \pm 0.04$ and $8.19 \pm 0.02$ for the blends with $20 \mathrm{wt} \%$ of AFP modified (MPF-20-M200) and unmodified (NMF-20-M200), respectively.

3.3. Mechanical Properties. The stress-strain diagrams of the composites of LDPE/AFP are presented in Figure 4. A typical behavior was observed for LDPE with elongation break up of $450 \%$ and the corresponding tensile stress of $13 \mathrm{MPa}$. The addition of AFP modified or unmodified promotes an increase in the tensile stress and a gradual decrease of the elongation at break as can be observed in Figure 4. However, the formulations containing AFP (200 mesh) modified by plasma at $5 \mathrm{wt} \%$ (MPF-5-M200) and at $20 \mathrm{wt} \%$ (MPF-20M200) further improve the tensile stress but present lower values of elongation percent than the composites with untreated AFP at 5 (NMF-5-M200) and $20 \mathrm{wt} \%$ (NMF-20M200). This behavior is due to the fact that the ethylene plasma treated AFP enhances the interfacial adhesion with the polyethylene matrix.

Young's modulus behavior as a function of the AFP content is presented in Figure 5. In a general way, the addition of untreated and treated AFP improves Young's modulus, but this improvement is higher for composites containing treated AFP (values higher than $10 \mathrm{wt} \%$ ). The composite with $20 \mathrm{wt} \%$ of AFP (200 mesh) labeled as MPF-M200 presented an increase of $21.7 \%$ in Young's modulus with respect to the composite at the same content of fiber $(20 \mathrm{wt} \%)$ unmodified (NMF-M200). This behavior could be explained by an 
TABLE 1: Mechanical properties of composites with pristine AFP at 5, 10, and $20 \mathrm{wt} \%$ (200 and 325 mesh).

\begin{tabular}{lcccc}
\hline Composite & AFP $(\%)$ & Young's modulus $(\mathrm{MPa})$ & Stress at break $(\mathrm{MPa})$ & Elongation at break $(\%)$ \\
\hline LDPE & 0 & $129.9 \pm 19.1$ & $13.3 \pm 0.3$ & $453.4 \pm 18.3$ \\
\hline NMF-5-M200 & 5 & $157.0 \pm 21.4$ & $10.6 \pm 0.5$ & $64.9 \pm 8.7$ \\
NMF-10-M200 & 10 & $173.9 \pm 15.0$ & $11.3 \pm 0.1$ & $46.1 \pm 1.2$ \\
NMF-20-M200 & 20 & $171.7 \pm 10.9$ & $10.4 \pm 0.2$ & $32.8 \pm 9.2$ \\
\hline NMF-5-M325 & 5 & $167.7 \pm 8.70$ & $11.2 \pm 0.4$ & $72.8 \pm 4.0$ \\
NMF-10-M325 & 10 & $185.0 \pm 15.0$ & $11.8 \pm 0.1$ & $42.4 \pm 7.4$ \\
NMF-20-M325 & 20 & $231.8 \pm 6.30$ & $12.7 \pm 0.4$ & $18.6 \pm 4.0$ \\
\hline
\end{tabular}

TABLE 2: Mechanical properties of composites containing plasma treated AFP at 5, 10, and $20 \mathrm{wt} \%$ (200 and 325 mesh).

\begin{tabular}{lcccc}
\hline Composite & AFP $(\%)$ & Young's modulus $(\mathrm{MPa})$ & Stress at break $(\mathrm{MPa})$ & Elongation at break (\%) \\
\hline LDPE & 0 & $129.9 \pm 19.1$ & $13.3 \pm 0.3$ & $453.4 \pm 18.3$ \\
\hline MPF-5-M200 & 5 & $167.7 \pm 12.5$ & $10.5 \pm 0.3$ & $48.4 \pm 16.0$ \\
MPF-10-M200 & 10 & $175.3 \pm 6.40$ & $10.5 \pm 0.2$ & $33.1 \pm 8.20$ \\
MPF-20-M200 & 20 & $209.0 \pm 12.3$ & $11.8 \pm 0.4$ & $15.7 \pm 1.10$ \\
\hline MPF-5-M325 & 5 & $174.2 \pm 6.07$ & $11.1 \pm 0.2$ & $109.1 \pm 35.9$ \\
MPF-10-M325 & 10 & $194.5 \pm 11.9$ & $11.4 \pm 0.4$ & $41.10 \pm 8.20$ \\
MPF-20-M325 & 20 & $221.9 \pm 9.40$ & $10.4 \pm 0.4$ & $13.90 \pm 3.90$ \\
\hline
\end{tabular}

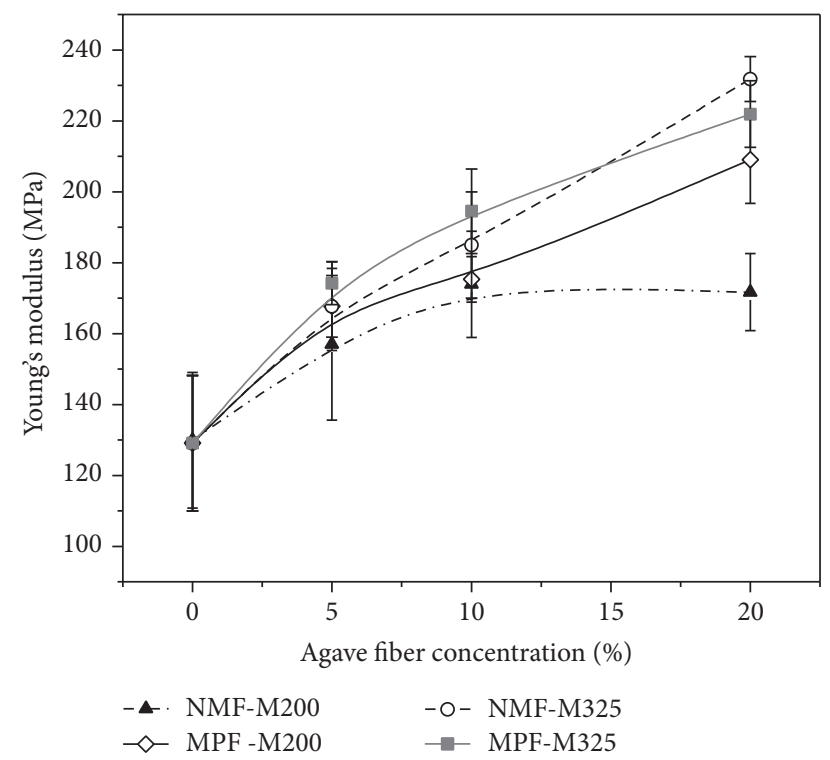

FIGURE 5: Young's modulus of the composites base of LDPE and AFP modified and unmodified.

increase in the interactions between the treated surface of AFP and the polyethylene matrix.

As a function of the size (200 to 325 mesh) of the AFP modified (MPF-M325) and unmodified (NMF-M325), there is no significant difference in Young's modulus of the composites especially at contents of AFP lower than $10 \mathrm{wt} \%$. Other authors obtained similar results previously, where plasma treatments with argon and air were used to improve the bonding strength between sisal fibers and polypropylene [30].
Other mechanical properties of composites are summarized in Tables 1 and 2. All composites have a tendency to decrease in the stress at break value in relation to the stress at break value of LDPE. A similar behavior was also observed for the results of the elongation at break of composites, indicating that the AFP modified transfers its elastic nature to the LDPE and reduces the tenacity of the composites.

3.4. Thermal Properties. The thermal properties of the composites such as percent of crystallinity, melting $\left(T_{m}\right)$, and crystallization $\left(T_{c}\right)$ temperatures are shown in Table 3. $T_{m}$ and $T_{c}$ were not significantly affected by the addition of both untreated and treated AFP, while an increase in the degree of crystallinity $\left(X_{c}\right)$ was observed and it was a function of the AFP content. It is well known that the fibers have a nucleating effect in the matrix promoting an increase in the crystallinity.

The crystallinity of composites with 5 and $20 \mathrm{wt} \%$ of AFP (200 mesh) modified (MPF-5-M200 and MPF-20-M200, respectively) is slightly greater than those composites with untreated AFP. This could be a result of a better dispersion and compatibility between treated AFP and polyethylene, since plasma treatment of AFP increased their compatibility towards the polymer matrix. However, the composite with $20 \mathrm{wt} \%$ of AFP (200 mesh) unmodified (NMF-20-M200) has slightly higher crystallinity than the composite prepared with treated AFP at the same content of agave fiber (MPF-20$\mathrm{M} 200$ ) and this could be related to the saturation of the system associated with a better dispersion of AFP in the matrix.

3.5. Scanning Electron Microscopy. Figure 6(a) shows a SEM micrograph of cryogenic fractures of composites that contained unmodified AFP, where the characteristic morphology of AFP can be seen and in the interphase there is a hole 
TABLE 3: Thermal properties obtained by DSC of composites at different content of AFP.

\begin{tabular}{lcccc}
\hline Blend & AFP $(\%)$ & $T_{m}\left({ }^{\circ} \mathrm{C}\right)$ & $T_{c}\left({ }^{\circ} \mathrm{C}\right)$ & \\
\hline LDPE & & 112.7 & 98.6 & \\
\hline NMF-5-M200 & 5 & 112.4 & 98.3 & 35.6 \\
NMF-10-M200 & 10 & 112.3 & 98.3 & 35.2 \\
NMF-20-M200 & 20 & 112.4 & 99.0 & 37.4 \\
\hline NMF-5-M325 & 5 & 113.1 & 99.0 & 38.4 \\
NMF-10-M325 & 10 & 120.2 & 98.0 & 35.0 \\
NMF-20-M325 & 20 & 119.6 & 99.8 & 35.9 \\
\hline MPF-5-M200 & 5 & 112.4 & 98.9 & 39.0 \\
MPF-10-M200 & 10 & 111.8 & 98.7 & 36.2 \\
MPF-20-M200 & 20 & 112.3 & 99.4 & 38.2 \\
\hline MPF-5-M325 & 5 & 112.2 & 99.1 & 37.4 \\
MPF-10-M325 & 10 & 112.1 & 98.5 \\
MPF-20-M325 & 20 & 112.5 & 99.3 \\
\hline
\end{tabular}

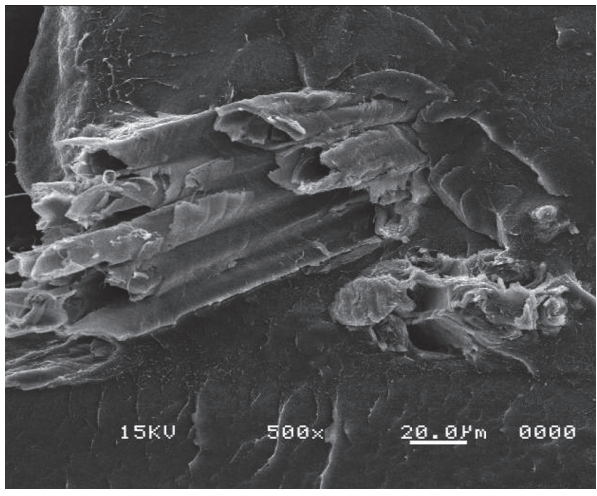

(a)

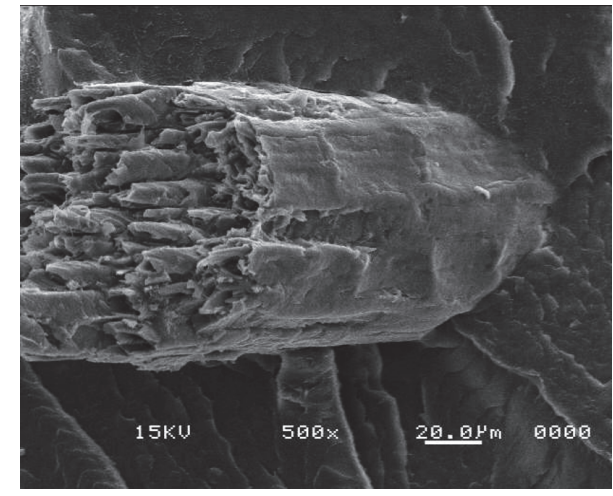

(b)

FIGURE 6: SEM micrographs of the composites with untreated and treated AFP. (a) NMF-20-M200 and (b) MPF-20-M200.

indicative of the lack of compatibility between phases due to the difference in polarity of both components [9]. However, the composites containing plasma treated AFP present a good adherence with the polymer matrix, which is associated with the good interfacial adhesion between the two phases, and the adhesion was improved by the plasma treatment of AFP (Figure 6(b)). This evidence of compatibility explains why the composites containing treated AFP had better Young's modulus.

\section{Conclusions}

The addition of ethylene plasma treated AFP improves the interfacial adhesion with the polyethylene matrix, since the coating applied by plasma on AFP has chemical nature similar to the polymer. The composites containing $20 \mathrm{wt} \%$ of AFP (200 mesh) modified (MPF-20-M200) presented an increase of $21.7 \%$ in Young's modulus with respect to the composites containing AFP unmodified (NMF-20-M200). Also the presence of the AFP promotes an increase of the degree of crystallinity of LDPE but did not affect significantly its crystallization and melting temperature. These results provided new insights on the use of agave fibers, especially if they are chemically modified to change their surface characteristics, and thus they could be used in a wide number of different applications such as reinforced polymer composites among others.

\section{Competing Interests}

The authors declare that they have no competing interests.

\section{Acknowledgments}

The authors thank the Mexican National Council of Science and Technology (CONACYT) for their financial support through Grant 232706 and the Laboratorio Nacional de Materiales Grafénicos, CONACYT (Project 250848) for the financial support. The authors also wish to thank Myriam Lozano, M. G. Méndez-Padilla, J. F. Zendejo-Rodríguez, and J. L. Saucedo-Morales for their technical support in the preparation and characterization of the composites. 


\section{References}

[1] A. K. Bledzki and J. Gassan, "Composites reinforced with cellulose based fibres," Progress in Polymer Science, vol. 24, no. 2, pp. 221-274, 1999.

[2] G. Iñiguez-Covarrubias, R. Díaz-Teres, R. Sanjuan-Duenas, J. Anzaldo-Hernández, and R. M. Rowell, "Utilization of byproducts from the tequila industry. Part 2: potential value of Agave tequilana Weber azul leaves," Bioresource Technology, vol. 77, no. 2, pp. 101-108, 2001.

[3] Tequila Regulatory Council CRT, 2015, http://www.crt.org.mx/.

[4] F. J. Aranda-García, R. González-Núñez, C. F. Jasso-Gastinel, and E. Mendizábal, "Water absorption and thermomechanical characterization of extruded starch/poly(lactic acid)/agave bagasse fiber bioplastic composites," International Journal of Polymer Science, vol. 2015, Article ID 343294, 7 pages, 2015.

[5] A. S. Singha and R. K. Rana, "Natural fiber reinforced polystyrene composites: effect of fiber loading, fiber dimensions and surface modification on mechanical properties," Materials \& Design, vol. 41, pp. 289-297, 2012.

[6] S. Leduc, J. R. G. Ureña, R. González-Núñez, J. R. Quirarte, B. Riedl, and D. Rodrigue, "LDPE/agave fibre composites: effect of coupling agent and weld line on mechanical and morphological properties," Polymers and Polymer Composites, vol. 16, no. 2, pp. 115-123, 2008.

[7] R. Z. Guzmán, F. A. Belmontes, S. A. Romero, and A. E. Monje, "Degradation of blue agave bagasse in low-density polyethylene composites under different processing conditions," Journal of Composite Materials, vol. 48, no. 30, pp. 3827-3835, 2014.

[8] T. Desmet, R. Morent, N. De Geyter, C. Leys, E. Schacht, and P. Dubruel, "Nonthermal plasma technology as a versatile strategy for polymeric biomaterials surface modification: a review," Biomacromolecules, vol. 10, no. 9, pp. 2351-2378, 2009.

[9] N. Dilsiz, "Plasma surface modification of carbon fibers: a review," Journal of Adhesion Science and Technology, vol. 14, no. 7, pp. 975-987, 2000.

[10] S. Mukhopadhyay and R. Fangueiro, "Physical modification of natural fibers and thermoplastic films for composites-a review," Journal of Thermoplastic Composite Materials, vol. 22, no. 2, pp. 135-162, 2009.

[11] R. Li, L. Ye, and Y.-W. Mai, "Application of plasma technologies in fibre-reinforced polymer composites: a review of recent developments," Composites Part A: Applied Science and Manufacturing, vol. 28, no. 1, pp. 73-86, 1997.

[12] X. Yuan, K. Jayaraman, and D. Bhattacharyya, "Effects of plasma treatment in enhancing the performance of woodfibre-polypropylene composites," Composites Part A: Applied Science and Manufacturing, vol. 35, no. 12, pp. 1363-1374, 2004.

[13] Y. Seki, K. Sever, M. Sarikanat, H. Gulec, and I. Tavman, "The influence of oxygen plasma treatment of jute fibers on mechanical properties of jute fiber reinforced thermoplastic composites," in Proceedings of the 5th International Advanced Technologies Symposium, Karabuk, Turkey, May 2009.

[14] J. Morales, M. G. Olayo, G. J. Cruz, P. Herrera-Franco, and R. Olayo, "Plasma modification of cellulose fibers for composite materials," Journal of Applied Polymer Science, vol. 101, no. 6, pp. 3821-3828, 2006

[15] L. A. Calva, F. Soriano, E. Hernández et al., "Surface modification of agave fibers by ethylene plasma and its effect on the mechanical properties of composites based polyethylene," in Proceedings of the 24th International Materials Research Congress, Cancún, Mexico, August 2015.
[16] M. G. Neira-Velázquez, E. Hernández-Hernández, L. F. RamosdeValle et al., "Chemical modification of carbon nanofibers with plasma of acrylic acid," Plasma Processes and Polymers, vol. 10, no. 7, pp. 627-633, 2013.

[17] B. Na, Q. Zhang, Q. Fu, G. Zhang, and K. Shen, "Super polyolefin blends achieved via dynamic packing injection molding: the morphology and mechanical properties of HDPE/EVA blends," Polymer, vol. 43, no. 26, pp. 7367-7376, 2002.

[18] B. Smith, Infrared Spectral Interpretation, CRC Press, Boca Raton, Fla, USA, 1999.

[19] G. Íñiguez, A. Valadez, R. Manríquez, and M. V. Moreno, "Utilization of by-products from the tequila industry. part 10: characterization of different decomposition stages of agave tequilana webber bagasse using ftir spectroscopy, thermogravimetric analysis and scanning electron microscopy," Revista Internacional de Contaminacion Ambiental, vol. 27, no. 1, pp. 6174, 2011.

[20] M. A. Nanny and N. Ratasuk, "Characterization and comparison of hydrophobic neutral and hydrophobic acid dissolved organic carbon isolated from three municipal landfill leachates," Water Research, vol. 36, no. 6, pp. 1572-1584, 2002.

[21] O. Faix, "Classification of lignins from different botanical origins by FT-IR spectroscopy," Holzforschung, vol. 45, no. 1, pp. 21-28, 1991.

[22] H. E. Emam and T. Bechtold, "Cotton fabrics with UV blocking properties through metal salts deposition," Applied Surface Science, vol. 357, pp. 1878-1889, 2015.

[23] M. Grube, E. Zagreba, E. Gromozova, and M. Fomina, “Comparative investigation of the macromolecular composition of mycelia forms Thielavia terrestris by infrared spectroscopy," Vibrational Spectroscopy, vol. 19, no. 2, pp. 301-306, 1999.

[24] R. Bodîrlâu and C. A. Teacâ, "Fourier transform infrared spectroscopy and thermal analysis of lignocellulose fillers treated with organic anhydrides," Romanian Reports of Physics, vol. 54, no. 1-2, pp. 93-104, 2009.

[25] H. Kobayashi, A. T. Bell, and M. Shen, "Plasma polymerization of saturated and unsaturated hydrocarbons," Macromolecules, vol. 7, no. 3, pp. 277-283, 1974.

[26] H. Z. Wang, M. W. Rembold, and J. Q. Wang, "Characterization of surface properties of plasma-polymerized fluorinated hydrocarbon layers: surface stability as a requirement for permanent water repellency," Journal of Applied Polymer Science, vol. 49, no. 4, pp. 701-710, 1993.

[27] L. Agres, Y. Ségui, R. Delsol, and P. Raynaud, "Oxygen barrier efficiency of hexamethyldisiloxane/oxygen plasma-deposited coating," Journal of Applied Polymer Science, vol. 61, no. 11, pp. 2015-2022, 1996.

[28] A. R. Denes, M. A. Tshabalala, R. Rowell, F. Denes, and R. A. Young, "Hexamethyldisiloxane-plasma coating of wood surfaces for creating water repellent characteristics," Holzforschung, vol. 53, no. 3, pp. 318-326, 1999.

[29] Z. Zhou, X. Liu, B. Hu et al., "Hydrophobic surface modification of ramie fibers with ethanol pretreatment and atmospheric pressure plasma treatment," Surface and Coatings Technology, vol. 205, no. 17-18, pp. 4205-4210, 2011.

[30] X. Yuan, K. Jayaraman, and D. Bhattacharyya, "Plasma treatment of sisal fibres and its effects on tensile strength and interfacial bonding," Journal of Adhesion Science and Technology, vol. 16, no. 6, pp. 703-727, 2002. 

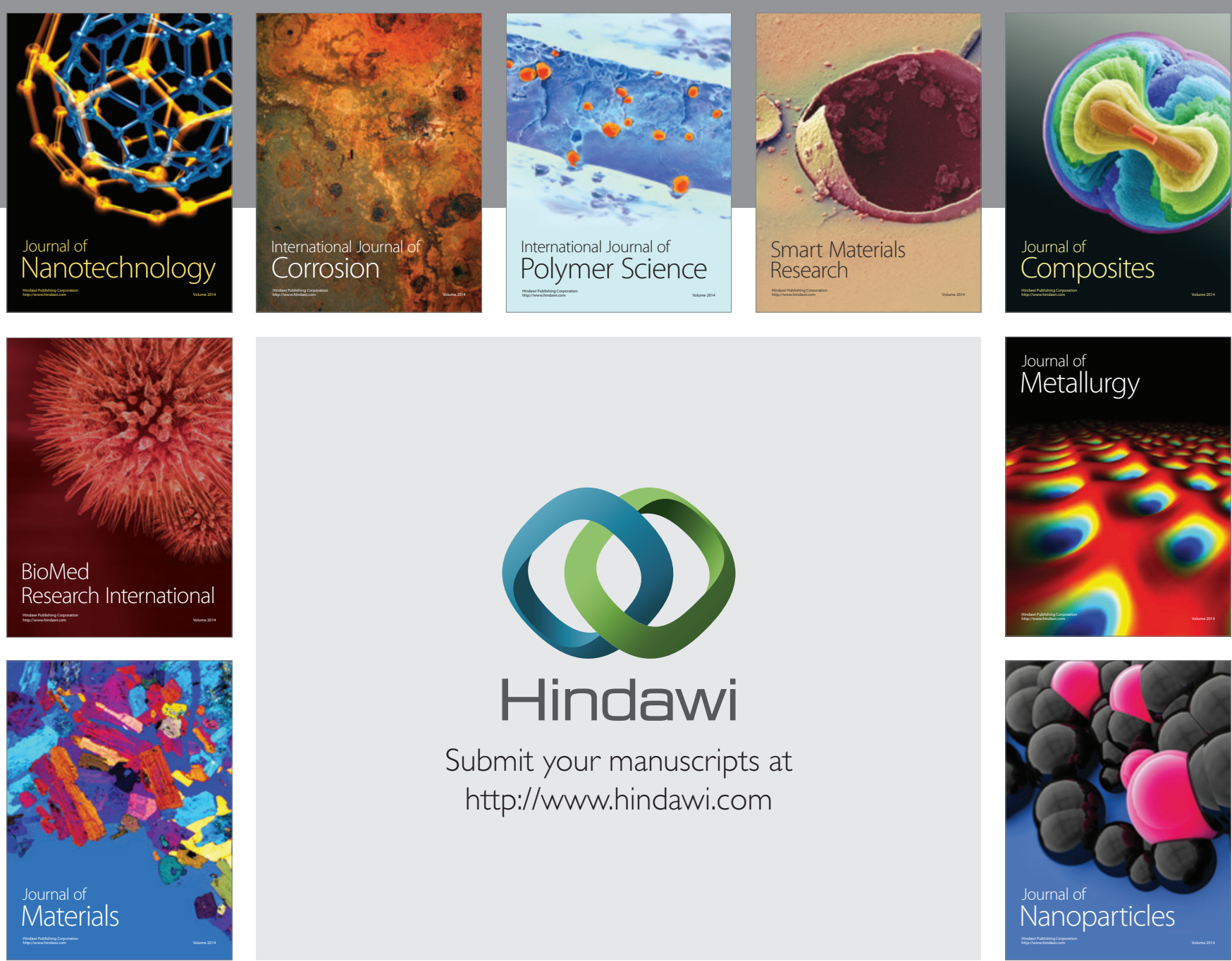

\section{Hindawi}

Submit your manuscripts at

http://www.hindawi.com

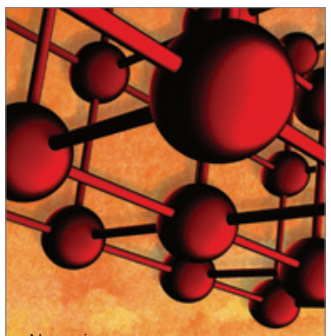

Materials Science and Engineering
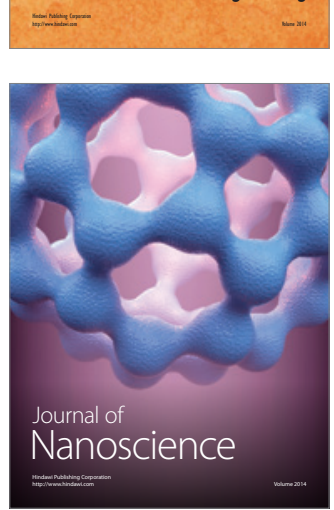
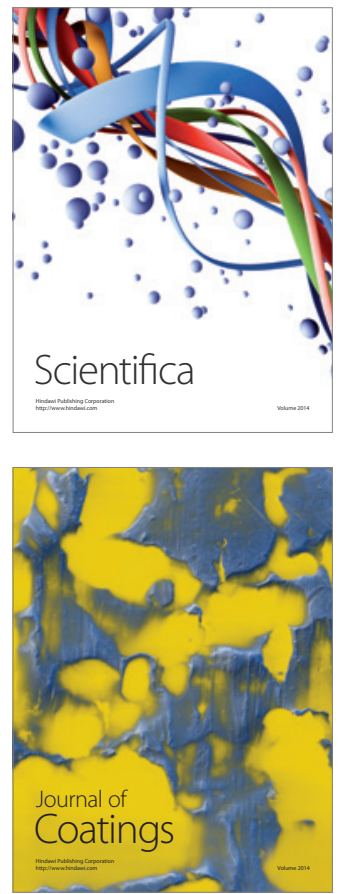
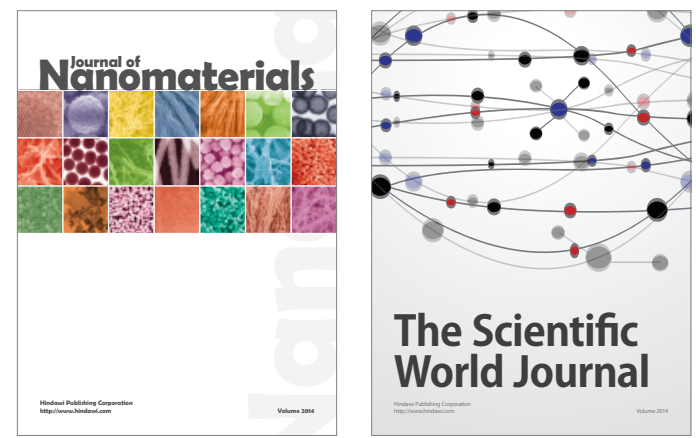

The Scientific World Journal
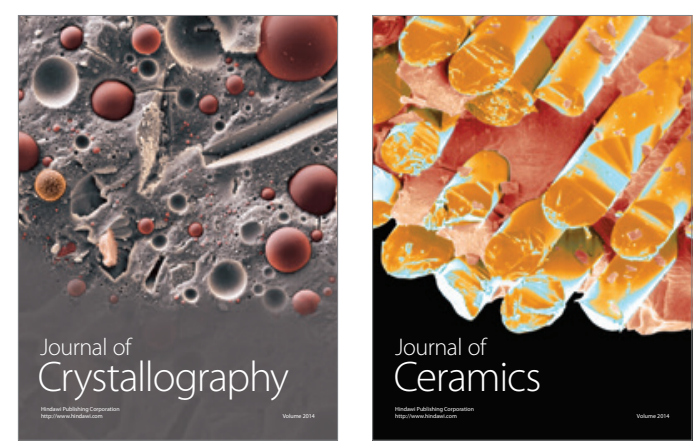
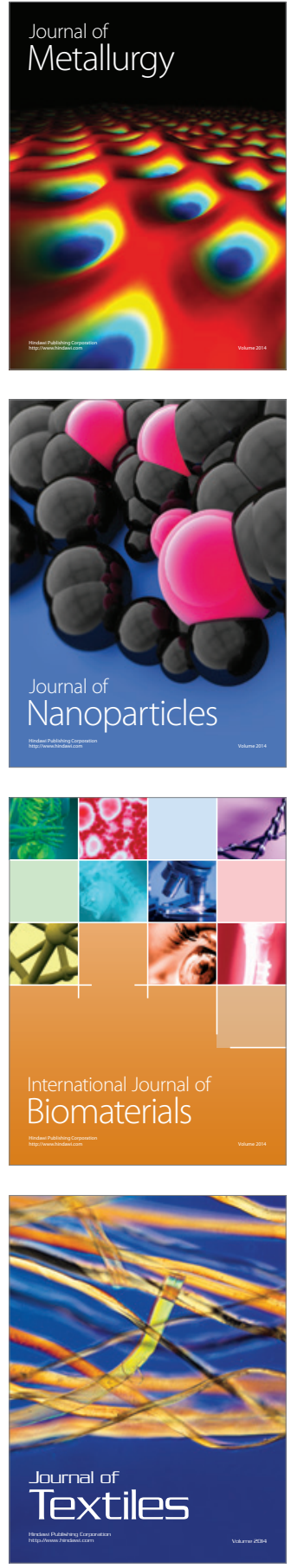